\title{
Glucocorticoid exposure and tissue gene expression of $11 \beta$ HSD-1, $11 \beta$ HSD-2, and glucocorticoid receptor in a porcine model of differential fetal growth
}

\author{
Christopher J McNeil, Margaret O Nwagwu ${ }^{1,2}$, Angela M Finch, Kenneth R Page ${ }^{1}$, Alan Thain ${ }^{2}$, \\ Harry J McArdle and Cheryl J Ashworth ${ }^{2}$ \\ Rowett Research Institute, Bucksburn, Aberdeen AB21 9SB, UK, ${ }^{1}$ School of Medical Sciences, University of Aberdeen, \\ Aberdeen AB25 2ZD, UK and ${ }^{2}$ Sustainable Livestock Systems Group, Scottish Agricultural College, Roslin BioCentre, \\ Roslin, Midlothian EH25 9PS, UK
}

Correspondence should be addressed to C J Ashworth; Email: cheryl.ashworth@sac.ac.uk

\begin{abstract}
Glucocorticoids play a critical role in fetal development, but inappropriate exposure is associated with reduced fetal growth. We investigated cortisol exposure and supply in a porcine model of differential fetal growth. This model compares the smallest fetus of a litter with an average-sized sibling at three stages of gestation. At day 45, small fetuses had reduced plasma cortisol (16.8 \pm $3.4 \mathrm{ng} / \mathrm{ml}$ ) relative to average fetuses $(34.4 \pm 3.4 \mathrm{ng} / \mathrm{ml}, P<0.001)$. At day 65 levels had reduced in small and average fetuses to similar concentrations $(5.7 \pm 1.0 \mathrm{vs} 4.8 \pm 0.5 \mathrm{ng} / \mathrm{ml}, P=0.128)$. By day 100 , elevated levels were found in small fetuses $(10.7 \pm 1.5$ vs $7.6 \pm 0.7 \mathrm{ng} / \mathrm{ml}, P<0.001)$. Maternal plasma cortisol was unchanged over gestation (day 45, $56.7 \pm 21.6 \mathrm{ng} / \mathrm{ml}$; day $65,57.8 \pm$ $14.4 \mathrm{ng} / \mathrm{ml}$; day 100, $55.7 \pm 6.5 \mathrm{ng} / \mathrm{ml}$ ). We examined the cause of altered cortisol by investigating the fetal hypothalamicpituitary-adrenal axis through the measurement of adrenocorticotropic hormone and assessing exposure to maternal cortisol by quantifying placental 11 $\beta$-hydroxysteroid dehydrogenase-isoform 2 (11 $\beta$ HSD-2) gene expression. These data suggest that altered cortisol supply was of fetal origin. We examined organ glucocorticoid (GC) metabolism by the measurement of GC receptor (GR) and 11 -hydroxysteroid dehydrogenase-isoform $1(11 \beta \mathrm{HSD}-1)$ gene expression. We found that fetal organs have different temporal patterns of $11 \beta$ HSD-1 and GR expression, with the liver particularly sensitive to cortisol in late gestation. This study examines GC exposure in naturally occurring differential growth and simultaneously explores tissue GC sensitivity and handling, at three key stages of gestation.

Reproduction (2007) 133 653-661
\end{abstract}

\section{Introduction}

In humans and animals, inadequate fetal growth decreases postnatal survival, and is linked to increased risk of adult disease (Barker \& Clark 1997). In the pig, birth weight is the major determinant of neonatal survival and is, therefore, of major economic importance (Winters \& Stewart 1947). Inappropriate exposure to glucocorticoids (GCs) has been proposed as a common mechanism linking the varied causes of reduced fetal growth to common deleterious outcomes (Fowden \& Forhead 2004). GC administration during late gestation can increase fetal exposure to inappropriate levels resulting in fetal growth retardation in rats, sheep, pigs, monkeys, and humans (Sloboda et al. 2000, Seckl 2001, Cleasby et al. 2003). Despite this, as birth approaches it is normal for fetal GC levels to increase. This natural increase in GC exposure is vital for promoting the organ maturation required for postnatal survival. Altered GC levels are associated with induced and spontaneous fetal growth restriction. For example, the offspring of proteindeficient rats expressed GC-induced enzymes at an elevated level (Langley-Evans \& Nwagwu 1998) and in day 110 pig fetuses, plasma cortisol is negatively correlated with weight (Wise et al. 1991). Interestingly, this relationship may not hold earlier in gestation in the pig, as at day 35, fetal size positively correlates with cortisol level (Klemcke et al. 1999). Little is known about the role that GC exposure plays in non-induced (i.e. naturally occurring) reduced fetal growth, particularly early in gestation.

There are two main sources of fetal GC that may be altered during growth retardation; the fetal adrenal gland and maternally derived cortisol which diffuses across the placenta. The fetal adrenal gland, regulated by the 
hypothalamus and pituitary gland (the HPA axis), synthesizes an endogenous supply of GC. As early as day 50 of gestation, HPA axis cortisol synthesis contributes $77 \%$ of total supply, increasing to $94 \%$ by day 100 , and is, therefore, the major source of fetal cortisol (Klemcke 1995). Adrenocorticotrophic hormone (ACTH) is released by the anterior pituitary and its plasma concentration is an index of HPA axis activation (Challis et al. 2001).

The enzymes $11 \beta$ hydroxysteroid dehydrogenase isoforms 1 and 2 (11 $\beta$ HSD-1 and -2) are critical components of placental and fetal ability to regenerate and deactivate GCs. $11 \beta$ HSD-2 deactivates cortisol through conversion to the less active cortisone (Stewart et al. 1995, Klemcke \& Christenson 1996, Clarke et al. 2002). Placental $11 \beta$ HSD-2 is particularly important because maternal GC levels are up to tenfold higher than in the fetus, therefore, $11 \beta$ HSD-2 acts to prevent placental diffusion of GC (Seckl 2001, Clarke et al. 2002). Placental $11 \beta$ HSD-2 is downregulated in response to maternal undernutrition, protein deficiency, reduced oxygen conditions, to chemicals such as glycyrrhizic acid and through mutation of the $11 \beta$ HSD-2 gene (Dave-Sharma et al. 1998, Bertram et al. 2001, Alfaidy et al. 2002). In these examples, reduced placental $11 \beta \mathrm{HSD}-2$ is associated with inadequate fetal growth or increased GC exposure. Placental $11 \beta$ HSD-2 may, therefore, be an important factor in the regulation of maternal GC supply to the developing fetus. In the porcine placenta, $11 \beta \mathrm{HSD}-2$ expression and activity are present as early as day 24 , and $11 \beta \mathrm{HSD}-1$ by day 30 . It is known that porcine placental $11 \beta \mathrm{HSD}-2$ expression increases between days 50 and 100 of gestation (Klemcke \& Christenson 1996, Klemcke et al. 2003), however, the localization of these enzymes within the porcine placenta has not been described.

Although until relatively recently attention has focused on cortisol levels in the developing fetus, it has become evident that organ GC processing and sensitivity may both be altered by reduced fetal growth, and may therefore markedly affect fetal responses to GCs at an organ-specific level. $11 \beta$ HSD-1 regenerates cortisol from cortisone, acting to locally amplify the action of GCs in various tissues (Seckl \& Walker 2001). The importance of this enzyme has been demonstrated using transgenic mice that lack the $11 \beta$ $H S D$-1 gene. This model demonstrates that fetal lung development is retarded due to tissue $11 \beta$ HSD-1 deficiency (Hundertmark et al. 2002). Placental $11 \beta$ HSD-1 may act to enhance the GC supply during the crucial late gestation GC 'surge' (Speirs et al. 2004). Relatively little is known about the effect of fetal and placental $11 \beta$ HSD-1 on differential fetal growth, however, if tissue expression of this enzyme changes, both fetal exposure and sensitivity to GC could be markedly altered.

Tissue abundance of GC receptor (GR) also affects tissue sensitivity to GC. GR expression is critical for development, with transgenic mice carrying a disrupted $G R$ gene suffering severely retarded lung development and death within hours of birth through respiratory failure (Cole et al. 1995). Tissue GR expression in the offspring of rats fed a low protein diet is increased in a number of tissues, including liver and lungs (Bertram et al. 2001). Increased GR expression may be involved in the development of metabolic syndrome and obesity in adulthood and is, therefore, a candidate for the chronic programming effects caused by reduced fetal growth (Whorwood et al. 2002).

This study tested three main hypotheses: 1) inadequate fetal growth is associated with altered cortisol exposure at key stages of gestation, 2) altered cortisol exposure is caused by a modification in placental capacity for deactivation of maternal cortisol, and 3) inadequate fetal growth is associated with organ-specific alterations in GC handling and sensitivity.

\section{Materials and Methods}

\section{Animals and sampling}

Sampling experiments were carried out in two periods, each using different protocols for animal euthanasia. During the first period, all blood and tissue samples studied were obtained with the exception of the placenta. The second sampling period was dedicated to obtaining placental RNA.

During the first sampling period, on days $45(n=7), 65$ $(n=9)$, and $100(n=20)$ of gestation (term $=\sim 114$ days) pregnant Large White $\times$ Landrace sows $(n=36)$ were anesthetized by an i.m. injection of $5 \mathrm{ml}$ Zoletil (chlorohydrate of toleamine and zolazepam; Zoletil 100, Virbac S. A., Carros, France). Deep anesthesia was induced by inhalation of $8 \%$ halothane (Halothane $\mathrm{BP}$, Rhone-Poulanc chemicals Ltd, Bristol, UK) and medical oxygen (BOC gases, Manchester, UK). Euthanasia was performed by exsanguination and a sample of whole maternal blood was collected.

The gravid uterus was removed aseptically for dissection. Each conceptus was removed and the mass of the fetus measured. At day 45, the lightest fetus from each litter and a fetus of approximately average weight were designated the 'small' and 'average' respectively. At days 65 and 100, the identification was initially performed by palpation of the uterus and confirmed by measurement of fetal weight. Fetal blood was sampled by cardiac puncture using a sterile heparinized syringe. Immediately after blood sample collection, days 65 and 100 fetuses received a $1 \mathrm{ml}$ intracardiac injection of sodium pentobarbitone (Euthatal, Rhone Merieux, Essex, UK) to ensure rapid euthanasia. Fetal and maternal blood samples were centrifuged at $1500 \mathrm{~g}$, the plasma was collected and stored at $-20^{\circ} \mathrm{C}$. The liver, lungs, kidneys, and heart of the small and average fetuses were removed, dissected and frozen in liquid nitrogen before storage at $-80{ }^{\circ} \mathrm{C}$.

During the second sampling period, four sows per stage of gestation were sampled using a modified euthanasia method. Briefly, after anesthesia was induced using an i.m. 
injection of Zoletil, euthanasia was performed by i.v. injection of $15 \mathrm{ml}$ Somulose (sodium quinalbarbitone $400 \mathrm{mg} / \mathrm{ml}$, cinchocaine hydrochloride $25 \mathrm{mg} / \mathrm{ml}$; Arnolds Veterinary Products Ltd, Shropshire, UK). Following euthanasia, placental tissue supplying average and small fetuses was excised, snap frozen in liquid nitrogen, and stored at $-80^{\circ} \mathrm{C}$. All experimental procedures were conducted in accordance with the UK-Animals (Scientific Procedures) Act, 1986 following local ethical approval.

\section{Measurement of cortisol and ACTH in maternal and fetal plasma}

Plasma cortisol was measured by specific RIA according to the manufacturer's instructions (Diagnostic Product Corporation UK, Euro/DPC Ltd, Gwynedd, UK) after validation for porcine plasma (Mwanza et al. 2000). The assay sensitivity was $2 \mathrm{ng} / \mathrm{ml}$, mean interassay coefficient of variability $(\mathrm{CV})$ was $7.3 \%$ and intraassay $\mathrm{CV}$ was $6.0 \%$. ACTH was measured in a single-specific RIA using ${ }^{125}$ I-human ACTH and rabbit anti-human ACTH antiserum, validated for use on porcine plasma, as described by Jarvis et al. (2007). The assay sensitivity was 77 pg/ml and had an average intraassay CV of $7.1 \%$.

\section{RNA extraction and analysis by northern blotting}

\section{Total RNA preparation}

Total RNA extractions were performed by two methods. The first method (method A) obtained high quality RNA from heart, kidney, lung, and liver. This method proved sub-optimal for placental tissues, because of the presence of substantial lipophilic material. An alternative method (method B) was used to obtain high quality placental RNA. RNA obtained using both methods was of comparable quality when visualized using ethidium bromide staining, and was subsequently used for northern blotting.

\section{Method A}

Total RNA was extracted from the tissues of the smallest and an average-sized fetus carried by four to seven randomly selected sows at each stage of gestation. Frozen tissue was transferred directly to $1 \mathrm{ml} \mathrm{TRI} \mathrm{reagent} \mathrm{(Helena}$ Biosciences, Sunderland, UK) and homogenized using $3 \times$ $20 \mathrm{~s}$ bursts with an Ultra Turrux homegeniser, model T25 and left at room temperature for $5 \mathrm{~min}$. Chloroform $(0.2 \mathrm{ml})$ was added, the sample vortex mixed, and centrifuged at $12000 \mathrm{~g}$ for $15 \mathrm{~min}$ at $4{ }^{\circ} \mathrm{C}$. The aqueous phase was then collected, and RNA within this phase precipitated by incubation with $0.5 \mathrm{ml}$ isopropanol for 10 min at room temperature. RNA was then washed with $75 \%$ ethanol in RNAase free water, dissolved in RNAase free water, and stored at $-80{ }^{\circ} \mathrm{C}$ before use.

\section{Method B}

Placental tissues were homogenized in TRI reagent, and the homogenate was centrifuged at $12000 \mathrm{~g}$ for $10 \mathrm{~min}$, in order to remove insoluble contamination. After $5 \mathrm{~min}$ at room temperature, $0.2 \mathrm{ml}$ chloroform was added, and the solution mixed vigorously for $15 \mathrm{~s}$. The homogenate was then stored at room temperature for 10 min before phase separation by centrifugation at $12000 \mathrm{~g}$ for 15 min at $4{ }^{\circ} \mathrm{C}$. The aqueous phase was then transferred to a separate tube, and $1 \mathrm{vol}$ of $85 \%(\mathrm{v} / \mathrm{v})$ ethanol added. RNA from this was then extracted using the Qiagen RNAeasy columns using the standard centrifugationbased method (Qiagen). Briefly, the sample was applied to the silica column provided, washed with provided buffers before the bound RNA was eluted with RNAase free water. RNA was then stored at $-80^{\circ} \mathrm{C}$ before use.

RNA concentration was quantified spectrophotometrically (OD-260:280). Ten to twenty micrograms of total RNA were separated on a $1 \%$ agarose gel, visualized to confirm integrity, transferred to a nylon membrane (Hybond, Amersham International) using an electrophoretic wet transfer apparatus (Model TE 62, Pharmacia Biotech) and cross-linked with a u.v. cross-linker (U.v. Products, Upland, CA, USA).

\section{cDNA probes}

Specific porcine cDNA northern probes for $11 \beta$ HSD-1, $11 \beta$ HSD-2, and GR were prepared by the following method: cDNA from day 100 porcine fetal liver and kidney was prepared by RT using Superscript II RT kit (Invitrogen Life Technologies) using oligo-dT primers. PCR primers were then designed using the PRIMER3 online software (Rosen \& Skaletski 2000) using porcinespecific sequences obtained from the Institute for Genomic Research (TIGR). Primer sequence, predicted product sizes, and TIGR database accession numbers are detailed in (Table 1).

Table 1 PCR primer sequences.

\begin{tabular}{|c|c|c|c|}
\hline Gene/primer & Sequence & Product size $(b p)$ & TIGR accession number \\
\hline $11 \beta H S D-1 F$ & 5'-TCССТАTTСТGCAAGCAAGTTT-3' & 680 & TC219816 \\
\hline $11 \beta H S D-1 R$ & 5'-ACCAGGTGTGGATTGATAAGGT-3' & & \\
\hline $11 \beta H S D-2 F$ & 5'-CACCGTGTTGGAGTTGGATAG-3' & 577 & TC47747 \\
\hline $11 \beta H S D-2 R$ & 5'-CAAGTGCTCGATGTAGTCCTCA-3' & & \\
\hline$G R F$ & 5'-AAGTCATTGAACCCGAGGTG-3' & 509 & TC120388 \\
\hline$G R R$ & 5'-TCСТTСССТСТTGACAATGG-3' & & \\
\hline
\end{tabular}


PCRs were carried out using liver CDNA for $11 \beta$ HSD-1 and GR and kidney cDNA for $11 \beta$ HSD-2. PCR products were then separated by agarose gel electrophoresis, and products of the predicted size were excised and DNA extracted and purified using the QIAquick gel extraction kit (Qiagen). These gene fragments were then cloned using the pGEM, T-vector system (Promega) using the manufacturer's instructions. The identity of the cloned DNA fragments inserts was confirmed by sequencing. cDNA probes for northern blotting were generated by PCR using purified plasmid from transformed bacteria as the template, and the cloning site flanking, T7 and SP6 primers.

\section{Northern blotting}

Probes were radiolabeled with $\left(\alpha^{-}{ }^{32} \mathrm{P}\right)$-dCTP using the 'Ready-To-Go' DNA labelling kit (Amersham International). Membranes were pre-hybridized at $42{ }^{\circ} \mathrm{C}$ for 30 min in Ultrahyb (Ambion, Abingdon, UK). Hybridizations were carried out overnight at $42{ }^{\circ} \mathrm{C}$ and the membranes were washed at $42^{\circ} \mathrm{C}$ to a stringency of $0.1 \times$ SSC $(1 \times$ SSC is $0.15 \mathrm{M} \mathrm{NaCl} / 0.015 \mathrm{M}$ sodium citrate $)+$ $0.1 \%$ SDS. Radioactivity on the membranes was imaged using a phosphorimaging system (FLA-3000, Fuji). The mRNA was quantified as the amount of radioactivity hybridizing to the bands, corrected for nonspecific binding. Phosphorimager images were analyzed using ImageJ image analysis software (National Institutes of Health, Bethesda, Maryland, USA). This expression was corrected for any differences in RNA loading by reprobing the membrane for $18 \mathrm{~S}$ abundance, using a similar method as described above. When required, cross-membrane expression was calculated by the use of a common reference sample present on each membrane analyzed.

\section{Statistical analysis}

Fetal weights, plasma cortisol and ACTH concentrations, and $G R$ and $11 \beta-H S D$ gene expression, were analyzed for the effect of fetal size and stage of gestation and for any interaction by two-way ANOVA with data blocked for sow to account for the common maternal environment shared by the small and average siblings. Post-hoc analysis was performed using one-way ANOVA blocked for sow identity, to test for differences between fetal sizes at individual gestational stages.

Correlations between maternal and fetal cortisol concentrations, and between fetal cortisol and ACTH concentration were analyzed by Pearson's two-tailed correlation. For all analyses, differences with $P<0.05$ were considered significant.

\section{Results}

\section{Fetal weights}

Table 2 shows that at each stage studied, the fetus designated 'small' was significantly lighter than the
Table 2 Fetal weight in the smallest and an average-sized littermate from a subset of sampled dams.

\begin{tabular}{lccc}
\hline & & \multicolumn{2}{c}{ Fetal weight $(\mathrm{g})$} \\
\cline { 3 - 4 } Day & No. & Average & Small \\
\hline 45 & 10 & $20.5 \pm 0.8^{\mathrm{a}}$ & $16.3 \pm 1.1^{\mathrm{b}}$ \\
65 & 10 & $214.5 \pm 8.2^{\mathrm{c}}$ & $156.3 \pm 11.4^{\mathrm{d}}$ \\
100 & 10 & $1027.3 \pm 53^{\mathrm{e}}$ & $590.7 \pm 68^{\mathrm{f}}$ \\
\hline
\end{tabular}

Data are means \pm S.E.M. Weights not sharing superscripts differ significantly $(P<0.05)$.

average fetus from that litter. There was a significant interaction between fetal size and stage of gestation due to the increasing difference between sibling weights as gestation progressed. At day 45 of gestation, the small fetus was $80 \%$ of the weight of their average sibling, by day 65 this difference was $73 \%$, and by day 100 the small fetus was $58 \%$ of the weight of the average sibling.

\section{Plasma cortisol and ACTH concentrations}

Figure 1 shows that fetal plasma cortisol concentrations changed significantly with the stage of gestation $(P<0.001)$ and fetal size $(P=0.004)$. In average-sized fetuses, cortisol concentrations were highest at day $45(34.4 \pm 3.4 \mathrm{ng} / \mathrm{ml})$ decreasing sevenfold by day 65
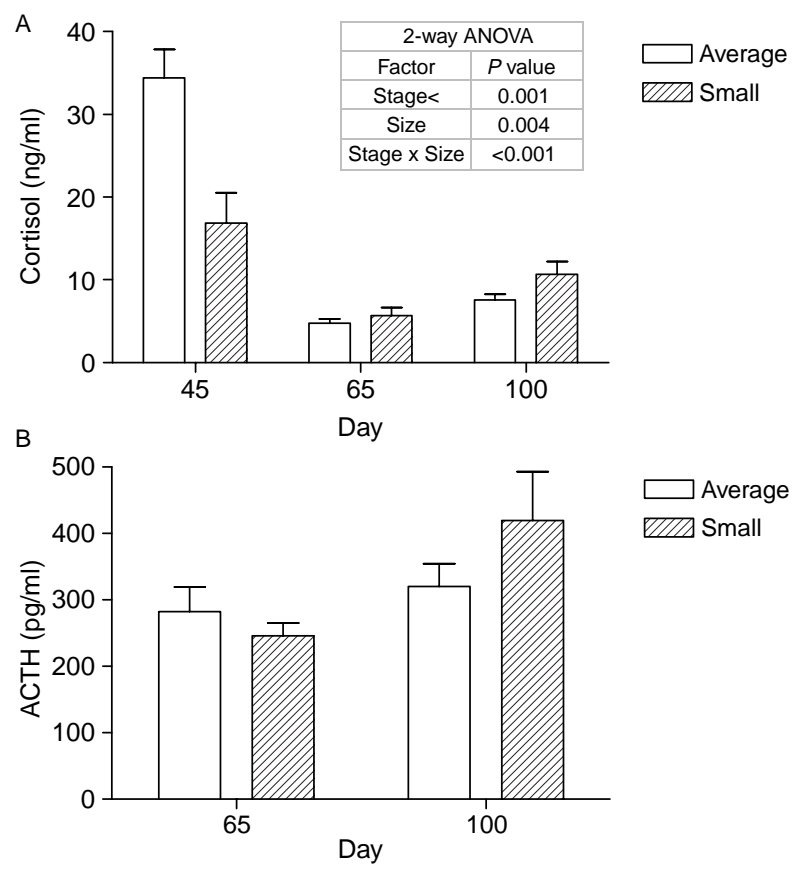

Figure 1 (A) Fetal plasma cortisol concentrations in small- and averagesized fetuses at three stages of gestation. Days 45, $n=6-7$ and $65, n=9$; day 100, $n=18-20$. (B) Fetal plasma ACTH concentrations in smalland average-sized fetuses at two stages of gestation. Data were analyzed for the effect of fetal size and stage of gestation and for any interaction by two-way ANOVA with data blocked for sow to account for the common maternal environment shared by the small and average siblings. Potential differences at individual stages were assessed by one-way ANOVA blocked for sow identity. 
$(4.8 \pm 0.5 \mathrm{ng} / \mathrm{ml})$ before again increasing $(7.6 \pm 0.7$ $\mathrm{ng} / \mathrm{ml}$ ) by day 100 of gestation. Although the small fetuses also demonstrated a similar temporal pattern, at day 45 they had $<50 \%$ of the plasma cortisol levels of their average siblings $(16.8 \pm 3.4 \mathrm{ng} / \mathrm{ml} ; P<0.001)$. At day 65 , cortisol in small fetuses $(5.7 \pm 1.0 \mathrm{ng} / \mathrm{ml})$ was not different from average, but at day 100 they had significantly elevated levels $(10.7 \pm 1.5 \mathrm{ng} / \mathrm{ml}$; $P=0.011)$ relative to their average-sized siblings. Maternal cortisol concentrations did not change with the stage of gestation (day $45,56.7 \pm 21.6 \mathrm{ng} / \mathrm{ml}$; day 65 , $57.8 \pm 14.4 \mathrm{ng} / \mathrm{ml}$; day $100,55.7 \pm 6.5 \mathrm{ng} / \mathrm{ml}$ ) and were greater than fetal concentrations at all stages. Maternal cortisol did not correlate with fetal levels at any stage of gestation, in either the small or average-sized fetuses (results not shown). The sex of a subset of fetuses sampled was determined during this experiment. From this subset, we found that out of 19 small fetuses with confirmed sex, 8 were male and 11 were female. Previous data have found that at day $100,50 \%$ of runt fetuses from this species were male (Finch et al. 2002). Together, these data suggest that there is no sex bias for the identity of the smallest fetus of the litter. Using day 100 data (with sufficient sex identified fetuses available for analysis), we tested for any affect of sex on plasma cortisol levels, to examine the possibility that sex may have affected the HPA axis. We did not find any effect of sex on plasma cortisol ( $P=0.985$, one-way ANOVA blocked for fetal size, $n=6-7$ per group). These analyses suggest that fetal sex did not significantly influence the fetal size:cortisol relationship described.

Plasma ACTH data were only obtained from days 65 and 100 fetuses, due to insufficient sample volume at day 45. Figure 1 shows that plasma ACTH concentrations were not different between fetal sizes at either day 65 , or day 100 . When the ACTH levels of the small fetuses were analyzed independent of average fetuses by one-way ANOVA, the increase in ACTH between days 65 and 100 approached statistical significance $(P=0.07)$. When this post-hoc analysis was repeated using only average-sized fetuses, no such evidence of increased ACTH was detected $(P=0.47$, days 65 vs 100; average fetuses only). Figure 2 shows that when plasma ACTH and cortisol concentrations of each day 65 fetus were plotted no correlation was revealed, however at day 100, a positive correlation that approached significance was detected $(P=0.06)$.

\section{$11 \beta-H S D-1,11 \beta-H S D-2$, and GR gene expression}

$11 \beta$ HSD-1 was detected in all tissues except the kidney. No fetal size related differences in $11 \beta$ HSD-1 expression were detected in any tissue at the three time points examined, however organ-specific temporal patterns of expression were observed. Placental $11 \beta$ HSD-1 decreased significantly through gestation (Table 3; $P=0.027$ ), in contrast, lung $11 \beta$ HSD-1 expression
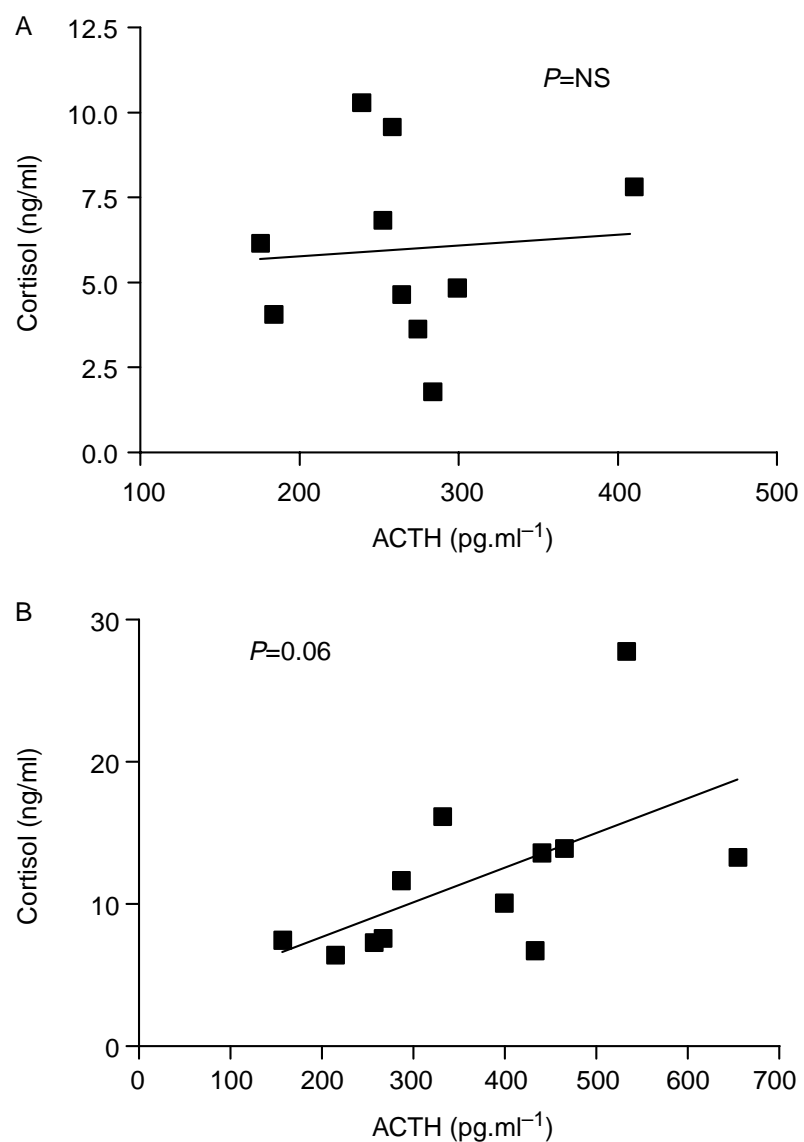

Figure 2 Correlation between fetal plasma ACTH and cortisol concentrations at (A) day $65(n=10)$ and (B) day $100(n=12)$ of gestation.

increased fourfold from days 45 to 100 (Table 4; $P<0.001)$ with the majority of this increase occurring between gestation days 65 and 100 . In the liver, $11 \beta$ HSD-1 expression increased by $>30 \%$ between days 45 and 100 (Table 5). In the heart, $11 \beta$ HSD-1 tended to increase throughout gestation (Table 6; $P=0.073$ ).

Expression of $11 \beta$ HSD-2 was detected in the placenta and fetal kidney but not in lung, liver, or heart tissue. Kidney $11 \beta$ HSD-2 increased sixfold from days 45 to 100 (Table 7; $P<0.001$ ) with expression in the small fetuses at day 45 significantly less than that of average-sized fetuses $(P=0.048)$. No size related expression differences in kidney $11 \beta$ HSD-2 were measured at days 65 and 100. Placental $11 \beta$ HSD-2 expression also increased through gestation (Table 2; $P=0.001$ ), however, no difference in expression was detected between small and average fetuses. This temporal pattern of placental $11 \beta$ HSD-2 regulation is opposite to that of $11 \beta$ HSD-1.

GR expression was detected in all tissues at the stages examined. The liver demonstrated the greatest temporal change in expression, increasing threefold from days 45 to 100 (Table 2; $P<0.001$ ). Overall, hepatic GR expression, when examined across gestation, was similar between small and average fetuses, however, post-hoc 
Table 3 Expression of $11 \beta$ HSD-1, $11 \beta$ HSD-2, and GR in placentas supplying small (s)- and average (a)-sized fetuses at three stages of gestation.

\begin{tabular}{|c|c|c|c|c|c|c|c|c|c|c|}
\hline \multirow[b]{2}{*}{ Gene } & & \multicolumn{2}{|c|}{ Day 45} & \multicolumn{2}{|c|}{ Day 65} & \multicolumn{2}{|c|}{ Day 100} & \multicolumn{3}{|c|}{ Probability } \\
\hline & & a & s & a & $\mathrm{s}$ & a & $\mathrm{s}$ & Stage & Size & Interaction \\
\hline \multirow[t]{2}{*}{ HSD1 } & Mean & 1.363 & 1.286 & 1.199 & 1.300 & 0.963 & 0.970 & 0.027 & NS & NS \\
\hline & S.E.M. & 0.122 & 0.057 & 0.083 & 0.034 & 0.103 & 0.088 & & & \\
\hline \multirow{2}{*}{ HSD2 } & Mean & 0.728 & 0.726 & 0.814 & 0.829 & 1.056 & 1.021 & 0.001 & NS & NS \\
\hline & S.E.M. & 0.060 & 0.094 & 0.063 & 0.041 & 0.052 & 0.041 & & & \\
\hline \multirow[t]{2}{*}{$G R$} & Mean & 0.664 & 0.554 & 0.689 & 0.649 & 0.572 & 0.548 & NS & 0.023 & NS \\
\hline & S.E.M. & 0.069 & 0.022 & 0.091 & 0.082 & 0.045 & 0.040 & & & \\
\hline
\end{tabular}

Each gene is expressed relative to a reference sample. $n=4$ per group. Effect of gestation stage, fetal size, and any interaction was analyzed by two-way ANOVA.

analysis at individual stages revealed that day 45 small fetuses expressed $30 \%$ more GR than their siblings $(P<0.005)$. Of the other tissues examined, lung tissue GR significantly increased by $\approx 20 \%$ over gestation $(P=0.011)$ by day 100 . GR expression in the kidney, heart, and placenta was not related to gestational stage, however, placental GR expression was significantly lower in smaller fetuses $(P=0.023)$ over the three stages measured. Post-hoc analysis did not detect a difference at specific time points, suggesting a marginal change maintained over gestation.

\section{Discussion}

The present study describes the relationship between fetal size and plasma cortisol concentrations at three stages of gestation in the pig and provides new evidence of the factors associated with altered fetal cortisol concentrations. Fetal cortisol concentrations were positively correlated with fetal size on day 45 and negatively correlated with size on day 100 . The expression pattern of placental $11 \beta$ HSD- 1 and -2 and fetal ACTH concentrations suggest altered cortisol was not caused by compromised placental protection from maternal cortisol. Inadequate fetal growth was associated with tissue-specific altered cortisol sensitivity, as assessed by GR expression, but not GC handling as measured by $11 \beta$ HSD-1 expression. These data revealed marked, tissue-specific temporal regulation of GR and $11 \beta$ HSD-1 through gestation, enabling us to better predict the impact of fluctuating GC levels on different organs through gestation.
At day 45, fetal cortisol levels were at their highest level of gestation, but with lower cortisol levels in the smallest when compared with average fetuses. Fetal cortisol exposure is influenced by altered supply from the mother or synthesis by the fetal adrenal gland. Studies, carried out at gestation day 50 in the pig, show $78 \%$ of fetal cortisol was of fetal origin at this early stage (Klemcke 1995). At day 45 , placental $11 \beta \mathrm{HSD}-2$ expression was detected and did not differ between small and average fetuses. This suggests the presence of placental protection from maternal cortisol, a conclusion supported by the lack of correlation between maternal and fetal cortisol levels. Between days 45 and 65, plasma cortisol reduced markedly, resulting in similar levels between small and average fetuses. At day 65 , fetal ACTH did not correlate with cortisol levels, suggesting low adrenal ACTH sensitivity. Reduced mid-gestation adrenal ACTH sensitivity has been observed in other species, and this mechanism may contribute to reduced cortisol levels (Wintour et al. 1995). By day 65, placental $11 \beta$ HSD-1 and -2 had decreased and increased respectively, in a pattern that predicts reduced cortisol transfer, potentially contributing to reduced fetal cortisol. By gestation day 100 , fetal cortisol levels increased in small and average fetuses. The greater increase in small fetuses resulted in their elevated cortisol relative to average fetuses. Increased prenatal cortisol is mediated by HPA-axis activation concurrent with reduced $11 \beta$ HSD-2 and increased $11 \beta \mathrm{HSD}-1$ in the placenta (Matthews \& Challis 1996, Ma et al. 2003). The temporal patterns in $11 \beta$ HSD-1 and - 2 expressions, and the lack of maternal:fetal plasma cortisol correlation suggest the placental barrier to maternal cortisol was patent at day 100. In contrast,

Table 4 Expression of $11 \beta$ HSD-1 and GR in lungs from small (s)- and average (a)-sized fetuses at three stages of gestation.

\begin{tabular}{|c|c|c|c|c|c|c|c|c|c|c|}
\hline \multirow[b]{2}{*}{ Gene } & & \multicolumn{2}{|c|}{ Day 45} & \multicolumn{2}{|c|}{ Day 65} & \multicolumn{2}{|c|}{ Day 100} & \multicolumn{3}{|c|}{ Probability } \\
\hline & & a & $\mathrm{s}$ & a & $\mathrm{s}$ & a & $\mathrm{s}$ & Stage & Size & Interaction \\
\hline \multirow[t]{2}{*}{ HSD1 } & Mean & 0.309 & 0.284 & 0.441 & 0.527 & 1.183 & 1.231 & $<0.001$ & NS & NS \\
\hline & S.E.M. & 0.050 & 0.040 & 0.071 & 0.022 & 0.142 & 0.113 & & & \\
\hline \multirow[t]{2}{*}{$G R$} & Mean & 0.932 & 0.990 & 0.889 & 0.986 & 1.103 & 1.171 & 0.011 & NS & NS \\
\hline & S.E.M. & 0.064 & 0.085 & 0.032 & 0.030 & 0.048 & 0.086 & & & \\
\hline
\end{tabular}

Each gene is expressed relative to a reference sample. $n=6$ per group. Effect of gestation stage, fetal size, and any interaction was analyzed by two-way ANOVA. 
Table 5 Expression of $11 \beta$ HSD-1 and GR in livers from small (s)- and average (a)-sized fetuses at three stages of gestation.

\begin{tabular}{|c|c|c|c|c|c|c|c|c|c|c|}
\hline \multirow[b]{2}{*}{ Gene } & & \multicolumn{2}{|c|}{ Day 45} & \multicolumn{2}{|c|}{ Day 65} & \multicolumn{2}{|c|}{ Day 100} & \multicolumn{3}{|c|}{ Probability } \\
\hline & & $\mathrm{a}$ & s & $\mathrm{a}$ & $\mathrm{s}$ & $\mathrm{a}$ & $\mathrm{s}$ & Stage & Size & Interaction \\
\hline \multirow[t]{2}{*}{ HSD1 } & Mean & 0.605 & 0.582 & 0.589 & 0.601 & 0.786 & 0.810 & 0.001 & NS & NS \\
\hline & S.E.M. & 0.020 & 0.023 & 0.014 & 0.031 & 0.022 & 0.024 & & & \\
\hline \multirow{2}{*}{$G R$} & Mean & 0.093 & $0.126^{*}$ & 0.200 & 0.210 & 0.277 & 0.286 & $<0.001$ & NS & NS \\
\hline & S.E.M. & 0.011 & 0.010 & 0.021 & 0.012 & 0.009 & 0.022 & & & \\
\hline
\end{tabular}

Each gene is expressed relative to a reference sample. $n=7$ per group. Effect of gestation stage, fetal size, and any interaction was analyzed by two-way ANOVA. * significantly different $(P<0.05)$ between sizes at that gestational stage.

increasing plasma ACTH in the small fetuses between days 65 and 100, and the correlation between ACTH and cortisol, both observations approaching statistical significance, hint at early HPA axis activation and enhanced adrenal ACTH sensitivity in small fetuses. Our data do not support the hypothesis that altered placental $11 \beta$ HSD-2 is the mechanism for altered GC levels. It is interesting to note that cortisol administered to the ovine feto-placental unit downregulates placental $11 \beta$ HSD-2 (Clarke et al. 2002). It is tempting to hypothesize that if reduced placental $11 \beta$ HSD-2 contributes to the prenatal cortisol surge in pigs, its downregulation may be a consequence of premature HPA axis activation and not a primary cause of increased cortisol.

These conclusions are based on the evidence that $11 \beta-H S D$ gene expression levels reflect net placental $11 \beta-$ HSD activity (Murotsuki et al. 1998, Stulnig et al. 2002). It is useful to highlight, however, that posttranslational regulation of $11 \beta-H S D$, as well as physical factors such as placental blood flow, also play a role in determining cortisol supply to the fetus. Furthermore, other mechanisms exist that can influence fetal cortisol abundance, and bioactivity. The liver metabolizes cortisol by glucuronidation (You 2004). The fetal activity of this pathway is unknown, as is its involvement, if any, with differential fetal growth. In addition, the bioavailability of plasma cortisol could be changed if the abundance of the cortisol-binding globulin was altered in small fetuses (Heo et al. 2003). Future studies of these mechanisms are required to further increase our understanding of GC metabolism during differential fetal growth.

It is recognized that it is difficult to predict organ responses to plasma GC levels without information about organ-specific GC sensitivity and 'processing' capacity (Edwards et al. 1996, Ghosh et al. 2000). The strength of the present study is the ability to combine cortisol exposure data with tissue GR and $11 \beta$ HSD-1 expression patterns, to better predict organ responses to cortisol levels. GR was expressed in all tissues at all stages with the liver and the lung expressions increasing through gestation. In contrast, cardiac, placental, and renal GR expression did not change with gestational age. This pattern of expression reflects the central importance of cortisol induced, late gestation lung and liver maturation for postnatal survival. In these tissues, upregulated GR acts synergistically with increased plasma cortisol to amplify organ responses such as induction of hepatic gluconeogenic enzymes, or surfactant production in the lung (Fowden et al. 1993, Schmidt et al. 2004). In small fetuses at day 100, increased GC sensitivity in the lung and liver could increase the vulnerability of these organs to excess cortisol. Excess cortisol can downregulate growth critical hepatic genes, such as the insulin-like growth factors and cause lung dysfunction (Li et al. 1993, Nyirenda et al. 1998, Okajima et al. 2001).

Throughout gestation, placental GR expression in small fetuses was less than their average siblings. Cortisol promotes the development and function of the placenta, through enhanced differentiation and upregulated nutrient transport (Nacharaju et al. 2004, Jones et al. 2006). Therefore, reduced cortisol at day 45 , and lower placental GR may compromise placental development and function in small fetuses. This hypothesis is supported by our previous data that found reduced placental:fetal weight ratios in small fetuses at day 45 . Furthermore, the normal development of amino acid transport mechanisms as gestation progressed was

Table 6 Expression of $11 \beta$ HSD-1 and GR in hearts from small (s)- and average (a)-sized fetuses at three stages of gestation.

\begin{tabular}{|c|c|c|c|c|c|c|c|c|c|c|}
\hline \multirow[b]{2}{*}{ Gene } & & \multicolumn{2}{|c|}{ Day 45} & \multicolumn{2}{|c|}{ Day 65} & \multicolumn{2}{|c|}{ Day 100} & \multicolumn{3}{|c|}{ Probability } \\
\hline & & a & $\mathrm{s}$ & a & $\mathrm{s}$ & a & $\mathrm{s}$ & Stage & Size & Interaction \\
\hline \multirow[t]{2}{*}{ HSD1 } & Mean & 0.765 & 0.729 & 0.731 & 0.794 & 0.867 & 0.871 & 0.073 & NS & NS \\
\hline & S.E.M. & 0.065 & 0.051 & 0.026 & 0.034 & 0.066 & 0.056 & & & \\
\hline \multirow[t]{2}{*}{$G R$} & Mean & 0.806 & 0.837 & 0.848 & 0.914 & 0.887 & 0.891 & NS & NS & NS \\
\hline & S.E.M. & 0.072 & 0.041 & 0.052 & 0.047 & 0.076 & 0.042 & & & \\
\hline
\end{tabular}

Each gene is expressed relative to a reference sample. $n=7$ per group. Effect of gestation stage, fetal size, and any interaction was analyzed by two-way ANOVA. 
Table 7 Expression of $11 \beta$ HSD-2 and GR in kidneys from small (s)- and average (a)-sized fetuses at three stages of gestation.

\begin{tabular}{|c|c|c|c|c|c|c|c|c|c|c|}
\hline \multirow[b]{2}{*}{ Gene } & & \multicolumn{2}{|c|}{ Day 45} & \multicolumn{2}{|c|}{ Day 65} & \multicolumn{2}{|c|}{ Day 100} & \multicolumn{3}{|c|}{ Probability } \\
\hline & & a & s & a & $\mathrm{s}$ & a & $\mathrm{s}$ & Stage & Size & Interaction \\
\hline \multirow[t]{2}{*}{ HSD2 } & Mean & 0.224 & $0.141^{*}$ & 0.676 & 0.654 & 0.989 & 1.014 & $<0.001$ & NS & NS \\
\hline & S.E.M. & 0.054 & 0.043 & 0.050 & 0.078 & 0.133 & 0.147 & & & \\
\hline \multirow[t]{2}{*}{$G R$} & Mean & 1.604 & 1.492 & 1.279 & 1.266 & 1.226 & 1.320 & NS & NS & NS \\
\hline & S.E.M. & 0.128 & 0.301 & 0.131 & 0.076 & 0.156 & 0.151 & & & \\
\hline
\end{tabular}

Each gene is expressed relative to a reference sample. Day $45, n=4$; day $65, n=7$; day $100, n=6$ per group. Effect of gestation stage, fetal size, and any interaction was analyzed by two-way ANOVA. * significantly different $(P<0.05)$ between sizes at that gestational stage.

retarded in the placentas supplying small fetuses (Finch et al. 2004).

All organs examined, with the exception of the kidney, expressed $11 \beta$ HSD-1, demonstrating that fetal tissues augment their supply of cortisol through local regeneration by $11 \beta \mathrm{HSD}-1$. Lung $11 \beta \mathrm{HSD}-1$, in particular, increased markedly by day 100 , emphasizing the importance of cortisol for lung maturation. Tissue $11 \beta$ HSD-1 expression was not regulated to compensate for altered plasma GC levels, either under conditions of deficit (day 45 small fetuses) or surfeit (day 100 small fetuses). It is not known if cortisone levels, the substrate for $11 \beta$ HSD-1, were different between fetal sizes. If this was the case, it is possible that tissue cortisol supply through $11 \beta$ HSD-1 could change despite unaltered expression levels.

The function of renal $11 \beta \mathrm{HSD}-2$, as a gatekeeper enzyme for the MR, is reflected in its increased expression through gestation in a pattern that follows the development of the kidney as an active regulator of blood pressure (Moritz et al. 2005). Decreased renal $11 \beta$ HSD-2 expression in small fetuses at day 45 did not persist, and is unlikely to affect postnatal blood pressure.

In conclusion, we have demonstrated for the first time that plasma cortisol levels at 45 and 100 days of gestation in the porcine fetus differ between small and average siblings from the same litter and that these differences probably reflect alterations in fetal cortisol production rather than in maternal supply. We have also found organ-specific differences in markers of GC sensitivity and processing that allow a better understanding of the impact of the changes in fetal cortisol. Together, these findings make an important contribution to our understanding of GC metabolism and differential fetal growth.

\section{Acknowledgements}

This work was supported by the Scottish Executive Environment and Rural Affairs Department flexible funds. The authors thank the staff at Rowett and SAC Easter Howgate piggeries and thank Drs $\mathrm{H} \mathrm{N}$ Jones and $\mathrm{R} \mathrm{E}$ Tilley for assistance with tissue collection. We also thank Dr A F Parlow, Harbor-UCLA Medical Center, California, USA for the gift of human ACTH and (rabbit) human ACTH antiserum. Donkey anti-rabbit IgG and rabbit sera were gifts from Diagnostics Scotland, Carluke, Lanarkshire, Scotland. The authors declare that there is no conflict of interest that would prejudice the impartiality of this scientific work.

\section{References}

Alfaidy N, Gupta S, DeMarco C, Caniggia I \& Challis JR 2002 Oxygen regulation of placental 11 beta-hydroxysteroid dehydrogenase 2 : physiological and pathological implications. Journal of Clinical Endocrinology and Metabolism 87 4797-4805.

Barker D \& Clark P 1997 Fetal undernutrition and disease in later life. Reviews of Reproduction 2 105-112.

Bertram C, Trowern AR, Copin N, Jackson AA \& Whorwood CB 2001 The maternal diet during pregnancy programs altered expression of the glucocorticoid receptor and type 2 11beta-hydroxysteroid dehydrogenase: potential molecular mechanisms underlying the programming of hypertension in utero. Endocrinology 142 2841-2853.

Challis JR, Sloboda D, Matthews SG, Holloway A, Alfaidy N, Patel FA, Whittle W, Fraser M, Moss TJ \& Newnham J 2001 The fetal placental hypothalamic-pituitary-adrenal (HPA) axis, parturition and post natal health. Molecular and Cellular Endocrinology 185 135-144.

Clarke KA, Ward JW, Forhead AJ, Giussani DA \& Fowden AL 2002 Regulation of 11 beta-hydroxysteroid dehydrogenase type 2 activity in ovine placenta by fetal cortisol. Journal of Endocrinology $\mathbf{1 7 2}$ 527-534.

Cleasby ME, Kelly PA, Walker BR \& SeckI JR 2003 Programming of rat muscle and fat metabolism by in utero overexposure to glucocorticoids. Endocrinology 144 999-1007.

Cole T, Blendy J, Monaghan A, Krieglstein K, Schmid W, Aguzzi A, Fantuzzi G, Hummler E, Unsicker K \& Schutz G 1995 Targeted disruption of the glucocorticoid receptor gene blocks adrenergic chromaffin cell development and severely retards lung maturation. Genes \& Development 9 1608-1621.

Dave-Sharma S, Wilson RC, Harbison MD, Newfield R, Azar MR, Krozowski ZS, Funder JW, Shackleton CHL, Bradlow HL, Wei J-Q et al. 1998 Examination of genotype and phenotype relationships in 14 patients with apparent mineralocorticoid excess. Journal of Clinical Endocrinology and Metabolism 83 2244-2254.

Edwards CR, Benediktsson R, Lindsay RS \& Seckl JR 199611 betaHydroxysteroid dehydrogenases: key enzymes in determining tissuespecific glucocorticoid effects. Steroids 61 263-269.

Finch AM, Antipatis C, Pickard AR \& Ashworth CJ 2002 Patterns of fetal growth within Large White $\mathrm{x}$ Landrace and Chinese Meishan gilt litters at three stages of gestation. Reproduction, Fertility and Development 14 419-425.

Finch AM, Yang LG, Nwagwu MO, Page KR, McArdle HJ \& Ashworth CJ 2004 Placental transport of leucine in a porcine model of low birth weight. Reproduction 128 229-235.

Fowden AL \& Forhead AJ 2004 Endocrine mechanisms of intrauterine programming. Reproduction 127 515-526. 
Fowden AL, Mijovic J \& Silver M 1993 The effects of cortisol on hepatic and renal gluconeogenic enzyme activities in the sheep fetus during late gestation. Journal of Endocrinology 137 213-222.

Ghosh B, Wood CR, Held GA, Abbott BD \& Lau C 2000 Glucocorticoid receptor regulation in the rat embryo: a potential site for developmental toxicity? Toxicology and Applied Pharmacology $164221-229$.

Heo J, Kattesh HG, Roberts MP \& Schneider JF 2003 Plasma levels of cortisol and corticosteroid-binding globulin (CBG) and hepatic CBG mRNA expression in pre- and postnatal pigs. Domestic Animal Endocrinology 25 263-273.

Hundertmark S, Dill A, Ebert A, Zimmermann B, Kotelevtsev YV, Mullins JJ \& Seckl JR 2002 Foetal lung maturation in 11 betahydroxysteroid dehydrogenase type 1 knockout mice. Hormone and Metabolic Research 34 545-549.

Jarvis S, Moinard C, Robson SK, Summer B, Douglas AJ, SeckI JR, Russell JA \& Lawrence AB 2007 Effects of weaning age on the behavioural and neuroendocrine development of piglets. Applied Animal Behaviour Science (In Press).

Jones HN, Ashworth CM, Page KR \& McArdle HJ 2006 Cortisol stimulates System A amino acid transport and SNAT2 expression in a human placental cell line (BeWo). American Journal of Physiology. Endocrinology and Metabolism 291 E596-E603.

Klemcke H 1995 Placental metabolism of cortisol at mid- and late gestation in swine. Biology of Reproduction 53 1293-1301.

Klemcke H \& Christenson R 1996 Porcine placental 11 betahydroxysteroid dehydrogenase activity. Biology of Reproduction $\mathbf{5 5}$ 217-223

Klemcke HG, McGuire WJ \& Christenson RK 1999 Cortisol concentrations in early porcine embryos. Life Sciences 64 1307-1312.

Klemcke HG, Sampath Kumar R, Yang K, Vallet JL \& Christenson RK 2003 11beta-Hydroxysteroid dehydrogenase and glucocorticoid receptor messenger RNA expression in porcine placentae: effects of stage of gestation, breed, and uterine environment. Biology of Reproduction 69 1945-1950.

Langley-Evans SC \& Nwagwu M 1998 Impaired growth and increased glucocorticoid-sensitive enzyme activities in tissues of rat fetuses exposed to maternal low protein diets. Life Sciences 63 605-615.

Li J, Saunders J, Gilmour R, Silver M \& Fowden A 1993 Insulin-like growth factor-II messenger ribonucleic acid expression in fetal tissues of the sheep during late gestation: effects of cortisol. Endocrinology 132 2083-2089.

Ma XH, Wu WX \& Nathanielsz PW 2003 Gestation-related and betamethasone-induced changes in 11 beta-hydroxysteroid dehydrogenase types 1 and 2 in the baboon placenta. American Journal of Obstetrics and Gynecology 188 13-21.

Matthews SG \& Challis JRG 1996 Regulation of the hypothalamopituitary-adrenocortical axis in fetal sheep. Trends in Endocrinology and Metabolism 7 239-246.

Moritz KM, Jefferies A, Wintour EM \& Dodic M 2005 Fetal renal and blood pressure responses to steroid infusion after early prenatal treatment with dexamethasone. American Journal of Physiology. Regulatory, Integrative and Comparative Physiology 288 R62-R66.

Murotsuki J, Gagnon R, Pu X \& Yang K 1998 Chronic hypoxemia selectively down-regulates 11 beta-hydroxysteroid dehydrogenase type 2 gene expression in the fetal sheep kidney. Biology of Reproduction 58 234-239.

Mwanza AM, Madej A, Kindahl H, Lundeheim N \& Einarsson S 2000 Plasma levels of cortisol, progesterone, oestradiol-17 beta and prostaglandin F2 alpha metabolite after ACTH (Synacthen Depot) administration in ovariectomized gilts. Journal of Veterinary Medicine. A, Physiology, Pathology, Clinical Medicine 47 193-200.

Nacharaju VL, Divald A, McCalla CO, Yang L \& Muneyyirci-Delale O 200411 beta-Hydroxysteroid dehydrogenase inhibitor carbenoxolone stimulates chorionic gonadotropin secretion from human term cytotrophoblast cells differentiated in vitro. American Journal of Reproductive Immunology 52 133-138.

Nyirenda MJ, Lindsay RS, Kenyon CJ, Burchell A \& Seckl JR 1998 Glucocorticoid exposure in late gestation permanently programs rat hepatic phosphoenolpyruvate carboxykinase and glucocorticoid receptor expression and causes glucose intolerance in adult offspring. Journal of Clinical Investigation 101 2174-2181.

Okajima S, Matsuda T, Cho K, Matsumoto Y, Kobayashi Y \& Fujimoto S 2001 Antenatal dexamethasone administration impairs normal postnatal lung growth in rats. Pediatric Research 49 777-781.

Rosen S \& Skaletski H 2000 Primer3 on the WWW for general users and for biologist programmers. In Bioinformatics Methods and Protocols: Methods in Molecular Biology, pp 365-386. Eds S Krawetz \& S Misener. Totowa: Humana Press.

Schmidt M, Sangild PT, Blum JW, Andersen JB \& Greve T 2004 Combined ACTH and glucocorticoid treatment improves survival and organ maturation in premature newborn calves. Theriogenology 61 1729-1744

Seckl JR 2001 Glucocorticoid programming of the fetus; adult phenotypes and molecular mechanisms. Molecular and Cellular Endocrinology 185 61-71.

Seckl JR \& Walker BR 2001 Minireview: 11beta-hydroxysteroid dehydrogenase type 1- a tissue- specific amplifier of glucocorticoid action. Endocrinology 142 1371-1376.

Sloboda DM, Newnham JP \& Challis JR 2000 Effects of repeated maternal betamethasone administration on growth and hypothalamic-pituitary-adrenal function of the ovine fetus at term. Journal of Endocrinology 165 79-91.

Speirs HJ, Seckl JR \& Brown RW 2004 Ontogeny of glucocorticoid receptor and 11beta-hydroxysteroid dehydrogenase type-1 gene expression identifies potential critical periods of glucocorticoid susceptibility during development. Journal of Endocrinology 181 105-116.

Stewart PM, Rogerson FM \& Mason JI 1995 Type 211 betahydroxysteroid dehydrogenase messenger ribonucleic acid and activity in human placenta and fetal membranes: its relationship to birth weight and putative role in fetal adrenal steroidogenesis. Journal of Clinical Endocrinology and Metabolism 80 885-890.

Stulnig TM, Oppermann U, Steffensen KR, Schuster GU \& Gustafsson J-A 2002 Liver X receptors downregulate 11 beta-hydroxysteroid dehydrogenase type 1 expression and activity. Diabetes 51 2426-2433.

Whorwood CB, Donovan SJ, Flanagan D, Phillips DI \& Byrne CD 2002 Increased glucocorticoid receptor expression in human skeletal muscle cells may contribute to the pathogenesis of the metabolic syndrome. Diabetes 51 1066-1075.

Winters LMCJ \& Stewart HA 1947 A study of factors affecting survival from birth to weaning and total weaning weight of the litter of swine. Journal of Animal Science 6 288-296.

Wintour EM, Crawford R, McFarlane A, Moritz K \& Tangalakis K 1995 Regulation and function of the fetal adrenal gland in sheep. Endocrine Research 21 81-89.

Wise T, Stone RT \& Vernon MW 1991 Relationships of serum estriol, cortisol and albumin concentrations with pig weight at 110 days of gestation and at birth. Biology of the Neonate 59 114-119.

You L 2004 Steroid hormone biotransformation and xenobiotic induction of hepatic steroid metabolizing enzymes. ChemicoBiological Interactions 147 233-246.

Received 4 April 2006

First decision 14 June 2006

Revised manuscript received 30 October 2006

Accepted 1 November 2006 